\title{
C-KIT Expression Enhances the Leukemogenic Potential of 32D Cells
}

\author{
Qinglong Hu, Maryanne Trevisan, Yi Xu, Weifeng Dong, Stuart A. Berger, ${ }^{\star}$ Stewart D. Lyman, ${ }^{\star}$ and Mark D. Minden \\ Department of Medical Biophysics and Medicine, Ontario Cancer Institute, University of Toronto, Toronto, Ontario M4X 1K9; \\ *Wellesley Hospital Research Institute, Toronto, Ontario M4Y 1J3; University of Toronto, Toronto, Ontario; and ${ }^{\ddagger}$ Immunex Corporation, \\ Seattle, Washington 98101
}

\begin{abstract}
The growth of human leukemic cells in culture and in vivo is dependent upon the presence of hematopoietic growth factors. Most populations of human leukemic acute myeloblastic leukemia (AML) cells express c-Kit on their surface and respond to Kit ligand $(K L)$ in culture. To determine if this interaction was of potential significance in vivo we used a mouse model system.

32D cells, a murine $\mathrm{L}-3$-dependent myeloid cell line, were rendered $\mathrm{KL}$ responsive by transfection of the murine c-Kit. After injection of 32D or 32D-Kit cells into syngeneic hosts, animals bearing 32D-Kit cells, but not 32D cells, became moribund and were killed. These animals had circulating leukemic blast cells, infiltration of bone marrow, spleen, brain, liver, lung, and kidney. Cells recovered from some of the animals continued to be dependent upon $\mathrm{IL-3}$ or $\mathrm{KL}$ for growth while in other cases the cells were factor indepen-
\end{abstract} dent.

This model illustrates that the constitutive expression of c-Kit enhances the leukemic potential of $32 \mathrm{D}$ cells. The model will be useful for studying the progression of leukemia in vivo and testing whether interruption of the interaction of Kit and KL can affect the growth of leukemic cells. ( $J$. Clin. Invest. 1995. 95:2530-2538.) Key words: 32D • Kit • Kit ligand - leukemia - AML

\section{Introduction}

The growth of human acute myeloblastic leukemia (AML) ${ }^{1}$ cells in culture and in vivo is dependent upon the presence of growth factors. The requirement for growth factors in culture has been demonstrated by colony forming assays in which the growth of the cells is usually dependent upon the addition of a variety of growth factors (1-3); these include granulocytemacrophage colony-stimulating factor (GM-CSF), granulocyte colony-stimulating factor (G-CSF), IL-3, and kit ligand (KL)

Address correspondence to Mark D. Minden, Department of Medical Biophysics and Medicine, University of Toronto, Ontario Cancer Institute, 500 Sherbourne Street, Toronto, Ontario. Canada, M4X 1K99. Phone: 416-924-0671 ext. 5188; FAX: 416-926-6529.

Received for publication 1 August 1994 and in revised form 24 January 1995.

1. Abbreviations used in this paper: AML, acute myeloblastic leukemia; FMS, CSF-1 receptor; KL, kit ligand; MGF, must cell growth factor; mIL-3, murine IL-3; mKit, murine c-Kit; SCF, stem cell factor.

J. Clin. Invest.

(c) The American Society for Clinical Investigation, Inc.

0021-9738/95/06/2530/09 $\$ 2.00$

Volume 95, June 1995, 2530-2538 (also referred to as mast cell growth factor [MGF] [4], or stem cell factor [SCF] [5]). Other factors such as IL-1 and IL-6 synergize with the above factors to enhance colony formation $(3,6,7)$. Though colony formation may occur in the absence of added growth factor(s), these cells rarely continue to grow for long periods of time. Moreover, in many cases of factor independent growth, the leukemic cells are producing their own growth factors (8). It has been suggested that leukemic cells are dependent on growth factors in vivo, based on the dependence on growth factors in culture $(3,9)$. The important growth factor-growth factor receptor pairs that operate in vivo in leukemia have not been identified; $\mathrm{c}-\mathrm{Kit}$ and its ligand have characteristics that make them prime candidates for such a pair.

The c-Kit protein is a transmembrane tyrosine kinase receptor that is similar in structure to the CSF-1 receptor (FMS), the PDGF receptor and the flk-2/fit3 receptor (10-12). c-Kit is expressed by early haematopoietic cells (13). Naturally occurring mutations of c-Kit in mice lead to the $W$ phenotype characterized in part by a macrocytic anemia and a reduced number of CFU-S $(14,15)$. The ligand for c-Kit has been cloned and studied. The Kit ligand (KL) protein is expressed either as a membrane bound form that can be cleaved to give a soluble product, or as a membrane bound form that remains on the cell surface $(4,16,17)$. The protein is constitutively expressed by a variety of tissues including bone marrow stromal cells, liver, lung, kidney, brain, and gut (18-20). Mutations of $\mathrm{KL}$ result in the Steel phenotype that is grossly indistinguishable from mice carrying $W$ mutations.

A role for c-Kit and $\mathrm{KL}$ in leukemogenesis was suggested initially by the observation that $\mathrm{c}-\mathrm{Kit} \mathrm{mRNA}$ and protein are expressed by leukaemic cells in most cases of AML (21-23). There is both patient to patient and cell to cell variation in the level of expression of c-Kit on the surface of leukemic cells. More recent studies have shown that in tissue culture $\mathrm{KL}$ will support the clonal growth and self renewal capacity of colony forming cells (24). The persistent expression of c-Kit by leukaemic cells and the fact that $\mathrm{KL}$ is expressed at a relatively high level by normal tissues raises the possibility that the interaction between Kit and its ligand may be important in the development or maintenance of the leukaemic state. To investigate this in a model system we have introduced a murine c-Kit (mKit) cDNA into 32D cells, a nonleukemogenic factor-dependent murine cell line (25). These cells become dependent on $\mathrm{KL}$ for survival and growth and can lead to the development of leukaemia in syngeneic animals.

\section{Methods}

Cell lines. The cell line used in this study, 32D, was established from normal $\mathrm{C} 3 \mathrm{H} / \mathrm{HeJ}$ mouse bone marrow by the infection with the Friend murine leukaemia virus (25). The cells were maintained in $\alpha$-medium, $10 \%$ fetal calf serum (FCS) and $10 \mathrm{U} / \mathrm{ml}$ of murine IL-3 (mIL-3). The mIL-3 was used as a crude conditioned medium of a 
myeloma cell line X63Ag8-653 engineered to express mIL-3 (26). S1/ S14, a stromal cell line derived from S1/S1 fetal liver, was obtained from Dr. David Williams and maintained in $\alpha$-medium and $10 \%$ FCS (27). S10 bone marrow stromal cells were obtained from Dr. K. Dorshkind and maintained in $\alpha$-medium and 10\% FCS (28).

Vectors. A cDNA of mKit lacking the amino acids GNNK just 5' of the transmembrane region $(29,30)$ and with a truncation of $3^{\prime}$ nonencoding sequences was cloned into the XhoI-NotI sites of the retrovirus LXSNnot, resulting in LXSNnot-mKit (30). LXSNnot was derived from LXSN by introducing a NotI site just 3' of the BamH I site (31). The virus encodes a neo gene that allows for selection of cells infected with the virus by growth in G418.

Creation of mKit expressing and neo resistant cell lines. The cell line $32 \mathrm{mKit}(\mathrm{A4})$ was created at Immunex in Seattle as follows. LXSNnot-mKit plasmid was transfected into the ecotropic PG+86E packaging cell line and a G418 resistant clone expressing a high titre of virus selected. Supernatant containing virus was used to infect 32D cells and G418-resistant clones were selected. One of the clones (A4) which expressed $\mathrm{mKit}$ was selected for further study. The $\mathrm{K}$ series of Kit expressing 32D cell lines was created at the Ontario Cancer Institute. LXSNnot-mKit was introduced into 32D cells by electroporation $(1,000$ $\mathrm{V}$ and $25 \mu \mathrm{F}$ ) (32) and mKit expressing cells were selected for by exposing the cells to $200 \mathrm{ng} / \mathrm{ml}$ of murine $\mathrm{KL}(\mathrm{mKL})$ in the absence of IL-3.

A control population of $32 \mathrm{D}$ cells expressing neo, named 32Dneo, was created by electroporating the cells in the presence of retrovirus plasmid pBabe-neo and then selecting for resistant cells with $1 \mathrm{mg} / \mathrm{ml}$ of G418 (33).

Northern blot analysis. Northern blot analysis was carried out as previously described (34). RNA was isolated by lysing cells in guanidium thiocyanate and separation by cesium chloride gradient centrifugation (35). RNA was size separated by electrophoresis on $1.2 \%$ agarose formaldehyde gels and transferred to Gene Screen Plus. Hybridization was carried out according to the instructions of the supplier (Amersham, Arlington Heights, IL). Filters were washed to a final salt concentration of $1 \times \mathrm{SSC}$ at $65^{\circ} \mathrm{C}$ and exposed to Kodak XAR film (Eastman Kodak Co., Rochester, NY) with an intensifying screen at $-70^{\circ} \mathrm{C}$ overnight.

Probes. The probe used was the mKit cDNA excised from LXSNnot-mKit with XhoI and NotI. Probes were labeled to a high specific activity with $\left[{ }^{32} \mathrm{P}\right] \mathrm{dCTP}$ by random priming $(36,37)$.

Tissue culture. 32D, 32Dneo, and 32DmKit cells were maintained in $\alpha$-medium containing $10 \%$ FCS (growth medium) and $10 \mathrm{U} / \mathrm{ml}$ of mIL-3; in addition $1 \mathrm{mg} / \mathrm{ml}$ of $\mathrm{G} 418$ was added to the culture of 32DmKit and 32Dneo cells. 1,000 cells in $0.2 \mathrm{ml}$ of $\alpha$-medium containing $10 \%$ FCS were plated in triplicate in 96-well flat bottom plates (Linbro) with or without added growth factor to determine the growth rate. Plates were incubated at $37^{\circ} \mathrm{C}$ in a humidified atmosphere containing air and $5 \% \mathrm{CO}_{2}$ for $4 \mathrm{~d}$. The cells were stained with trypan blue and the number of viable cells determined using a haemocytometer.

To determine the presence of 32D cells in mice, animals were killed by cervical dislocation and single cell suspensions prepared from the bone marrow and spleen. $1 \times 10^{6}$ cells in $1 \mathrm{ml}$ of growth medium with or without $10 \mathrm{U} / \mathrm{ml}$ of IL-3 and with or without $1 \mathrm{mg} / \mathrm{ml}$ of G418 were plated in 24-well plates and incubated for $21 \mathrm{~d}$ in the conditions described above. The growth of cells was determined by visual observation and counting with a haemocytometer.

Mice. $\mathrm{C} 3 \mathrm{H} / \mathrm{HeJ}$ mice, 8-10 wk old, syngeneic with 32D cells, were used for all of the experiments (Jackson Laboratories, Bar Harbor, ME). In some experiments mice were irradiated using a ${ }^{137} \mathrm{Cs} \gamma$ source to give the indicated amount of irradiation. Cells were inoculated into mice by tail vein injection. Animals were killed by cervical dislocation either at designated times or when they became moribund. The experimental protocols have been reviewed and approved by the local Animal Experimentation Committee.

Histology. For the analysis of peripheral blood, tail veins were nicked with a scalpel and a drop of blood applied to a glass slide, spread, and stained sequentially with May, Grunwald, and Giemsa stain. Other organs were fixed in B-5 (spleen) or formalin (liver, kidney, brain, lung, and heart), embedded in paraffin, sectioned and stained with Hematoxylin and Eosin.

Production and biotinylation of $m K L$. Soluble recombinant murine $\mathrm{mKL}$ (amino acids 1-187) was produced in $E$. coli using a vector that directs secretion to the periplasmic space (S. A. Berger, manuscript in preparation). The periplasmic fraction was prepared by the method of Osborn and Munson (38) and $\mathrm{mKL}$ was purified by affinity chromatography with rabbit anti-mKL polyclonal antibodies (S. A. Berger, unpublished) immobilized on CnBr-activated Sepharose (Sigma Chemical Co., St. Louis, MO).

Murine $\mathrm{KL}$ was conjugated with biotin using the method described by Goding (39). Affinity purified protein was dialysed against $0.1 \mathrm{M}$ $\mathrm{NaHCO}_{3}$, pH 8.2. $60 \mu \mathrm{l}$ of biotin-succinimide ester (Calbiochem Corp., La Jolla, CA), freshly dissolved in DMSO to a concentration of $2 \mathrm{mg}$ / $\mathrm{ml}$ was added to $0.5 \mathrm{ml}$ of purified $\mathrm{mKL}(140 \mu \mathrm{g} / \mathrm{ml})$ and incubated at room temperature for $3 \mathrm{~h}$. The sample was then dialyzed extensively against phosphate buffered saline $/ 0.1 \%$ sodium azide. The sample was collected and bovine serum albumin (Boehringer Mannheim, Indianapolis, IN), was added as carrier to a final concentration of $1 \mathrm{mg} / \mathrm{ml}$. The biotinylated protein retained almost full activity as determined by stimulation of murine MC-9 mast cells as measured by ${ }^{3} \mathrm{HTdR}$ incorporation. In a 2-d assay the $D_{50}$ of the biotinylated protein (assuming no loss during dialysis) was $218 \mathrm{ng} / \mathrm{ml}$. In the same assay the $D_{50}$ of unconjugated protein was $150 \mathrm{ng} / \mathrm{ml}$.

The degree of conjugation was determined by competition for biotinylated-mKL bioactivity by streptavidin. The addition of streptavidin competed for $\mathrm{KL}$ activity in a dose dependent manner. The addition of $3 \mu \mathrm{g} / \mathrm{ml}$ of streptavidin completely eliminated stimulating activity of the conjugated $\mathrm{KL}$ without affecting the activity of unconjugated protein. The results indicate that the protein preparation was fully conjugated.

Cell surface Kit expression. To measure the cell surface expression of Kit, $1 \times 10^{6}$ cells in a minimum volume $(10 \mu \mathrm{l})$ of balanced salt solution containing $5 \%$ newborn calf serum (BSS $/ 5 \%$ NBS) were incubated with biotinylated $\mathrm{mKL}(140 \mu \mathrm{g} / \mathrm{ml})$ at a dilution of $1: 10$ for $1 \mathrm{~h}$ on ice. After two washes in BSS/5\% NBS the cells were incubated on ice with a 1:100 dilution of streptavidin-phycoerythrin (Southern Biotechnology) in BSS /5\%NBS for 20 min. The cells were then washed and analyzed. To further confirm Kit protein on the cell surface, ACK2, a monoclonal anti-mKit antibody (kindly provided by Dr. S. Nishikawa) was used to label cells (40). Briefly, $1 \times 10^{6}$ cells were incubated with the ACK-2 antibody at a concentration known to give maximum staining, in BSS/5\% NBS for 20 min on ice. After two washes in BSS/ $5 \%$ NBS the cells were incubated in FITC-conjugated mouse anti-rat IgG (Jackson Immuno-chemicals) at a dilution of 1:40 in BSS/5\% NBS for $20 \mathrm{~min}$ on ice. Cells were washed and analyzed on a FACScan (Becton Dickinson, Mountain View, CA). Primary antibody staining was preceded by blocking of $\mathrm{Fc}$ receptors with nonspecific mouse IgG (Calbiochem Corp.). Cells stained with either streptavidin-phycoerythrin or FITC-conjugated mouse anti-rat IgG alone (without primary antibody) were used as controls for background staining. Flow cytometric analysis was carried out using a FACScan ${ }^{\circledR}$ (Becton Dickinson) with an argon laser at $488 \mathrm{~nm}$.

Statistics. Statistical analysis was carried out using the Minitab program. Student's $t$ test was used to compare the difference of survival time between different groups of mice. Chi square was used to test the difference in the frequency of mice with growth factor independent cells. The Mann-Whitney test was used to compare the difference between spleen weights in control and experimental animals.

\section{Results}

Development and characterization of Kit expressing cell lines. The overall purpose of our studies was to examine the growth of Kit expressing 32D cells in syngeneic animals. To do this it was first necessary to obtain factor dependent cell lines that differed only in their expression of c-Kit. The first cKit expressing cell line that we studied was 32DmKit(A4) 


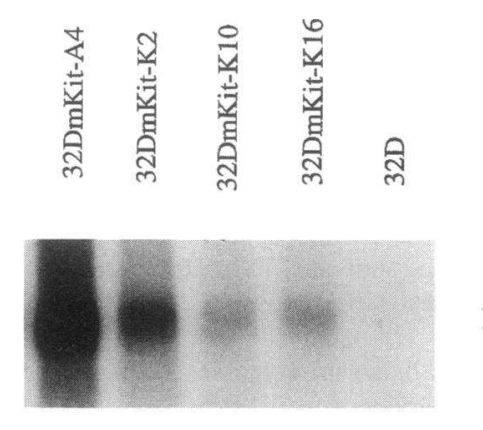

Figure 1. Northern blot analysis of RNA from 32D cells and 32DmKit cells. The blots were probed with a full length Kit mouse c-Kit cDNA. The upper panel illustrates the hybridization of Kit to RNA of the cell lines. The lower panel is the $28 \mathrm{~S}$ ribosomal band detected by ethidium bromide staining of the gel before transfer. The loading of RNA is approximately equal in the lanes.

which was isolated following retroviral infection of the c-Kit negative IL-3-dependent cell line 32D. Northern blot analysis revealed that 32DmKit(A4) cells and not 32D cells expressed large amounts of mKit RNA (Fig. 1). The presence of Kit protein on the cell surface was confirmed using biotinylated mKL or the anti-Kit antibody ACK-2 (Fig. 2). The response to growth factors of 32DmKit(A4) cells was compared with the parental cell line. 32D cells grew well in mIL-3, however, the cells rapidly lost viability in the absence of $\mathrm{mIL}-3$ or in the presence of $\mathrm{mKL}$. In contrast $32 \mathrm{DmKit}(\mathrm{A} 4)$ cells grew in suspension in IL-3 or $\mathrm{mKL}$ (Table $\mathrm{I}$ ). The growth rate of 32DmKit (A4) cells in mKL was somewhat slower than in $\mathrm{mIL}$ 3 (data not shown) and a lower saturation density was reached (Table I).

In a preliminary experiment $32 \mathrm{D}$ and $32 \mathrm{DmKit}(\mathrm{A} 4)$ cells were injected into lethally irradiated $\mathrm{C} 3 \mathrm{H} / \mathrm{HeJ}$ mice. 32DmKit (A4) cells, but not 32D cells resulted in the development of a leukemic state after 7 wk (data not shown).

The above results indicated that 32DmKit expressing cells could survive and proliferate in syngeneic animals. However, this could be explained by clonal variation possibly resulting from the site of integration of the retrovirus carrying the Kit cDNA. For this reason we generated the K series of Kit expressing lines by the electroporation of LXSNNot-mKit into 32D cells. Three independent cell lines, $32 \mathrm{mKit}(\mathrm{K} 2), 32 \mathrm{mKit}(\mathrm{K} 10)$ and 32DmKit(K16) were selected for their ability to survive and grow in $\mathrm{mKL}$ or $\mathrm{mIL}-3$; the cells died rapidly in the absence of growth factor.

Expression of Kit RNA and Kit protein. The amount of Kit RNA and protein was determined as part of the characterization of the cell lines. Northern blot analysis for Kit RNA revealed that there was a marked difference in the amount of message between the cell lines (Fig. 1). The 32DmKit(A4) cells had the largest amount of message while 32DmKit(K10) cells had the least. The variation in the amount of Kit message was reflected in the protein studies. The presence of cell surface Kit was determined by flow cytometry using either biotinylated mKL or ACK-2, an antibody directed against Kit (Fig. 2). Kit cell surface expression was greatest on 32DmKit(A4) cells followed by 32DmKit(K2), 32DmKit(K16), and 32DmKit(K10) cells.

Injection of $32 \mathrm{D}$ Kit cells into syngeneic animals. To deter-
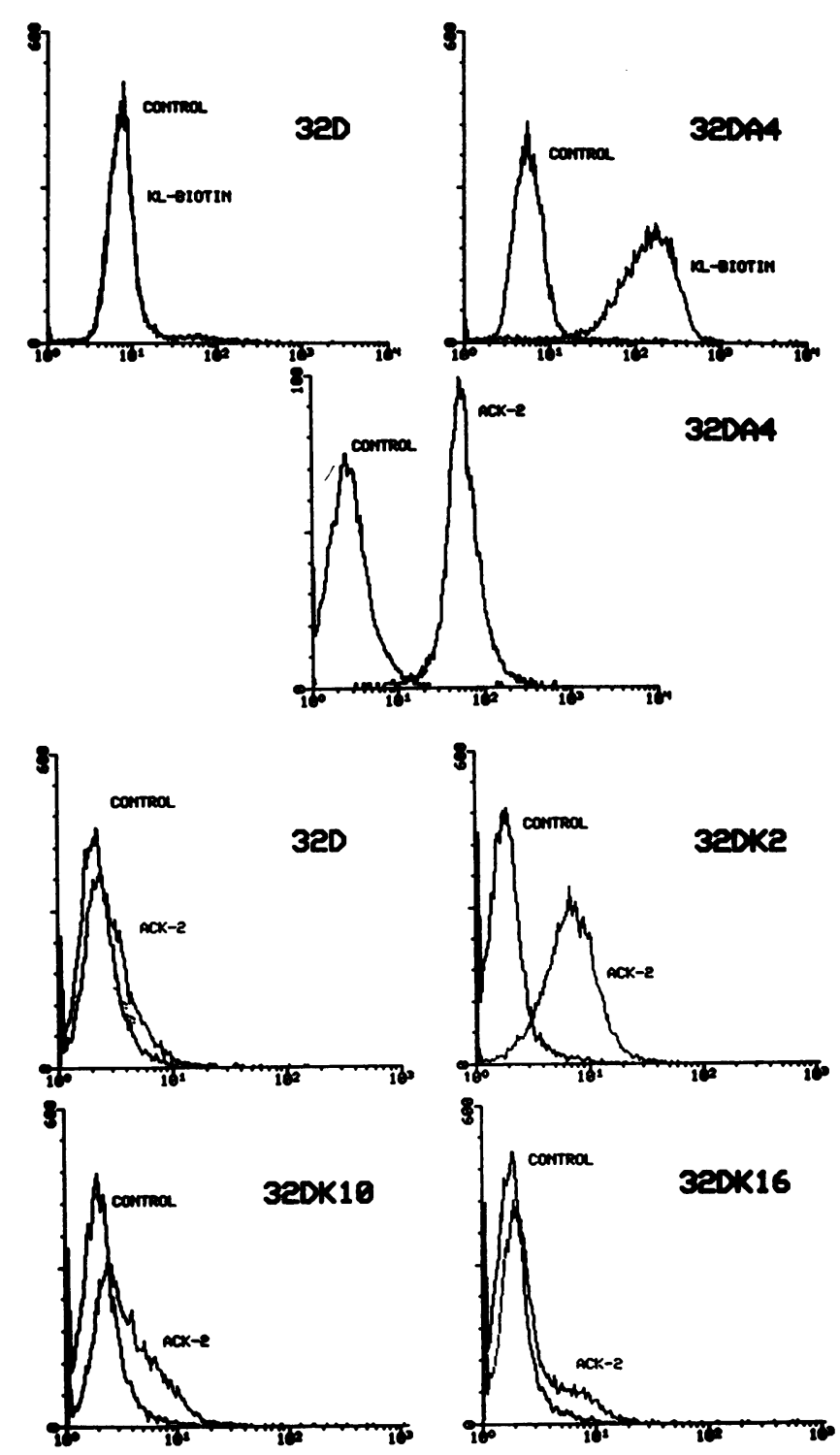

Figure 2. Cell surface Kit protein as detected by flow cytometry. The upper two panels illustrate the presence of cell surface Kit as detected with biotinylated-KL. The upper left panel demonstrates staining of 32D cells, while the right panel shows the staining of 32DmKit(A4) cells. In the remaining panels, ACK-2, an anti-Kit monoclonal antibody was used to detect the presence of Kit on the cell lines. The control cells are unstained. A low level of staining is seen on 32D cells, however, this is not different from the isotype control (data not shown).

mine the effect of the constitutive expression of Kit by 32D cells on their growth in vivo 32DmKit(A4), 32DmKit(K2), 32DmKit(K10), and 32DmKit(K16) cells were injected into lethally irradiated or unirradiated animals. The experimental design is outlined in Table II. To provide radioprotection to the irradiated animals and to allow sufficient time for the growth of the 32DmKit cells, the test cells lines were co-injected with $5 \times 10^{5}$ normal syngeneic bone marrow cells. In addition to the test group of animals there were two control groups. One control group of animals received normal bone marrow and 32D cells that expressed the neomycin resistance gene (32Dneo); the other control group of control animals received only normal 
Table I. Effect of IL-3 or KL on the Growth of $32 D$ or 32DmKit(A4) Cells

\begin{tabular}{ccc}
\hline Growth factor & 32D & 32DmKit(A4) \\
\hline 0 & 0 & 0 \\
IL-3 & $1.87 \times 10^{4}$ & $1.58 \times 10^{4}$ \\
$\mathrm{mKL}$ & 0 & $7 \times 10^{3}$
\end{tabular}

$3 \times 10^{3}$ in $0.2 \mathrm{ml}$ of $\alpha$ medium with $10 \%$ FCS and the indicated growth factor were placed in individual wells of a 96-well flat bottom plate. After $72 \mathrm{~h}$ of growth the number of cells were counted. IL-3 was used at a concentration of $10 \mathrm{U} / \mathrm{ml}$ and $\mathrm{mKL}$ at a concentration of $250 \mathrm{ng} /$ $\mathrm{ml}$, both of these had been shown to give the maximum stimulation.

bone marrow cells. The animals were observed on a daily basis (Table II).

Culture of cells from mice at three weeks. Limiting dilution studies in tissue culture with both 32D and 32DmKit(A4) cells indicated that over $50 \%$ of the cells have self renewal capacity in mIL-3 CM (data not shown). In the absence of IL-3 all of the cells die in less than a week. This very high plating efficiency and dependence on IL-3 provides a sensitive bioassay to determine the fate of $32 \mathrm{Dneo}$ and $32 \mathrm{mKit}$ cells following injection into mice. Mice were killed at 3 wk after injection and bone marrow and spleen cells were cultured with $(a)$ no growth factor, $(b)$ no growth factor plus G418, $(c) \mathrm{IL}-3$, or $(d)$ IL-3 plus G418. No G418 resistant cells were recovered from animals injected with only normal bone marrow or 32Dneo cells, either at 3 wk or up to 26 wk after injection. In contrast, G418 resistant cells were recovered from all of the mice injected with 32DmKit cells at 3 wk (Table III). By morphology the cells were identical to the parental cells. In most instances the cells were dependent upon the presence of IL-3 for viability and proliferation. Cells that were IL-3 dependent were also $\mathrm{KL}$ responsive. Cells that were G418 resistant and did not require IL-3 or mKL for growth, factor independent cells, were recovered from 1 of the 3 animals injected with 32DmKit(K10) cells and 2 of 3 animals injected with 32DmKit(K16) cells. Animals

Table II. Experimental Design

\begin{tabular}{lccccc}
\hline $\begin{array}{l}\text { Cell line } \\
\text { injected }\end{array}$ & $\begin{array}{c}\text { Irradiation } \\
{ }^{137} \mathrm{C}(\mathrm{cGy})\end{array}$ & $\begin{array}{c}\text { Number of } \\
\text { 32DmKit }\end{array}$ & $\begin{array}{c}\text { Normal } \\
\text { BM cells }\end{array}$ & $\begin{array}{c}\text { No. of mice } \\
\text { 3 wk }\end{array}$ & $\begin{array}{c}\text { No. of mice } \\
>6 \text { wk }\end{array}$ \\
\hline${\mathrm{A} 4(-)^{*}}^{*}$ & no & $10^{6}$ & 0 & 0 & 5 \\
${\mathrm{~A} 4-250^{\ddagger}}^{7}$ & 250 & $10^{6}$ & 0 & 0 & 5 \\
$\mathrm{~A} 4$ & 900 & $10^{6}$ & $5 \times 10^{5}$ & 3 & 5 \\
$\mathrm{~K} 2$ & 900 & $10^{6}$ & $5 \times 10^{5}$ & 3 & 5 \\
$\mathrm{~K} 10$ & 900 & $5 \times 10^{5}$ & $5 \times 10^{5}$ & 3 & 5 \\
$\mathrm{~K} 16$ & 900 & $10^{6}$ & $5 \times 10^{5}$ & 3 & 5 \\
Neo & 900 & $10^{6}$ & $5 \times 10^{5}$ & 6 & 8 \\
NBM & 900 & 0 & $5 \times 10^{5}$ & 3 & 3 \\
Total & & & & 21 & 41 \\
\end{tabular}

*A4(-), mice injected with 32DmKit(A4) cells were not irradiated.

${ }^{\ddagger} A 4-250$, mice injected with 32DmKit(A4) cells were irradiated to 250 cGy. All other groups of animals received 900 cGy. 32DNeo cells. $N B M$, normal mouse bone marrow cells. No. of mice $3 \mathrm{wk}$ is the number of mice in that group that were killed at $3 \mathrm{wk}$. No. of mice $>6 \mathrm{wk}$ is the number of mice in that group that were killed after $6 \mathrm{wk}$.
Table III. Cultures of Cells Recovered From Mice Injected with $32 \mathrm{D}$ and 32DmKit Cells

\begin{tabular}{lccccc}
\hline & \multicolumn{2}{c}{3 wk } & & \multicolumn{2}{c}{ After 6 wk } \\
\cline { 2 - 3 } \cline { 5 - 6 } Group & FID cells & G418 resistant & & FID cells & G418 resistant \\
\hline A4 & $0 / 3$ & $3 / 3$ & & $3 / 5$ & $5 / 5$ \\
K2 & $0 / 3$ & $3 / 3$ & & $2 / 4$ & $4 / 4$ \\
K10 & $1 / 3$ & $3 / 3$ & & $4 / 5$ & $5 / 5$ \\
K16 & $2 / 3$ & $3 / 3$ & & $3 / 4^{\dagger}$ & $3 / 4^{\ddagger}$ \\
A4-250 & ND & ND & & $4 / 5$ & $5 / 5$ \\
A4(-) & ND & ND & & $3 / 4$ & $4 / 4$ \\
Total & $4 / 15(27 \%)^{*}$ & $15 / 15$ & & $22 / 33(67 \%)^{*}$ & $32 / 33$ \\
NBM & $0 / 3$ & $0 / 3$ & & $0 / 3$ & $0 / 3$ \\
Neo & $0 / 6$ & $0 / 6$ & & $0 / 3$ & $0 / 3$ \\
& & & &
\end{tabular}

${ }^{*} P$ value $<0.01$. ${ }^{\ddagger}$ One animal was killed at day 72 , no G418 resistant/ IL-3-dependent cells were recovered at that time. The three animals containing G418 resistant cells became ill between days 135 and 154 and were killed at that time. The denominator is the number of mice at risk and the numerator is the number of mice containing FID or G418 resistant cells. $A 4(-)$, mice injected with 32DmKit(A4) cells were not irradiated. A4-250, mice injected with 32DmKit(A4) cells were irradiated to $250 \mathrm{cGy}$. All other groups of animals received $900 \mathrm{cGy}$. FID, factor independent. Neo, 32DNeo cells. NBM, normal mouse bone marrow cells.

that had been injected with 32Dneo cells were also killed at 7 and $150 \mathrm{~d}$; at neither of these times was it possible to recover IL-3 responsive and/or G418 resistant cells. These results indicate that 32DmKit cells but not 32Dneo cells could persist in syngeneic animals.

Development of leukemia in 32DmKit-injected animals. As mentioned above the animals were observed on a daily basis. Animals that had been injected with 32DmKit cells became progressively weak and moribund beginning at $\sim 6$ wk after the start of the experiment. These animals were killed and their organs examined for evidence of infiltration by leukaemic cells (Table IV).

A red blood cell count done at the time of death revealed that all of the animals injected with 32DmKit cells were anemic, whereas control animals had a normal red blood cell count. Peripheral blood analysis revealed a marked decrease in the number and frequency of normal mature lymphocytes and granulocytes and the presence of circulating blast cells (Fig. 3). In the bone marrow the majority of the cells were blast cells.

Gross anatomic examination revealed that the spleen was enlarged in all animals injected with 32DmKit cells in comparison to normal animals (Table V); there was no correlation between the size of the spleen and the presence of factor independent clones or the degree of expression of Kit by the 32D cells. Histologic examination of the spleen demonstrated almost complete replacement of the spleen by $32 \mathrm{DmKit}$ cells. Infiltration by blast cells was also observed in the liver, lung, kidney, gut, and brain. Infiltration of the liver began in the periportal area and extended into the liver lobule (Fig. 3). In some cases the liver architecture was totally disrupted. Infiltration of the brain was evident in two anatomic areas. Most frequently there was infiltration of the meninges, however in some cases there was also involvement of the white matter itself (Fig. 3). 
Table IV. Sites of Tissue Infiltration by 32DmKit Cells

\begin{tabular}{|c|c|c|c|c|c|c|c|c|c|}
\hline Group & Brain & Spleen & Liver & Lung & BM & Kid & Gut & Anemia & PBB* \\
\hline $\mathrm{A} 4(-)$ & $3 / 4$ & $4 / 4$ & $4 / 4$ & $2 / 4$ & $4 / 4$ & $2 / 4$ & $1 / 4$ & $4 / 4$ & $4 / 4$ \\
\hline $\mathrm{A} 4-_{250}$ & $5 / 5$ & $5 / 5$ & $5 / 5$ & $5 / 5$ & $5 / 5$ & $0 / 5$ & $2 / 5$ & $5 / 5$ & $5 / 5$ \\
\hline A4 & $2 / 5$ & $5 / 5$ & $4 / 5$ & $4 / 5$ & $5 / 5$ & $0 / 5$ & $1 / 5$ & $5 / 5$ & $5 / 5$ \\
\hline $\mathrm{K} 2$ & $4 / 4$ & $4 / 4$ & $4 / 4$ & $4 / 4$ & $4 / 4$ & $0 / 4$ & $2 / 4$ & $4 / 4$ & $4 / 4$ \\
\hline K10 & $4 / 4$ & $4 / 4$ & $4 / 4$ & $1 / 4$ & $4 / 4$ & $3 / 4$ & $2 / 4$ & $4 / 4$ & $4 / 4$ \\
\hline K16 & $3 / 3$ & $3 / 3$ & $3 / 3$ & $2 / 3$ & $3 / 3$ & $2 / 3$ & $2 / 3$ & $3 / 3$ & $3 / 3$ \\
\hline Total & $21 / 25$ & $25 / 25$ & $25 / 25$ & $18 / 25$ & $25 / 25$ & $7 / 25$ & $10 / 25$ & $25 / 25$ & $25 / 25$ \\
\hline
\end{tabular}

The denominator is the number of mice at risk and the numerator is the number of mice demonstrating that characteristic. $* P B B$, peripheral blood blasts. $A 4(-)$, mice injected with 32DmKit(A4) cells were not irradiated. $A 4{ }_{250}$, mice injected with 32DmKit(A4) cells were irradiated to $250 \mathrm{cGy}$. All other groups of animals received $900 \mathrm{cGy}$.

Involvement of the lung, kidney and gut was more variable among animals.

To determine whether cells isolated from leukemic animals maintained the ability to grow in syngeneic hosts, secondary transfers were performed. Factor-dependent and -independent cells isolated from diseased animals were transferred to irradiated syngeneic mice as described above. In either circumstance the cells engrafted and the animals became moribund. The time to developing signs of failure to thrive was similar to that for animals receiving 32DKit(A4) cells.

Development of factor independent growth. Some of the animals, studied 3 wk after injection, harboured 32DmKit cells that did not require added mIL-3 or mKL for survival and proliferation. The presence of factor-dependent and -independent cell lines in bone marrow and spleen at the time the animals became moribund was assessed in a manner identical to that at $3 \mathrm{wks}$. The proportion of animals containing factor independent cells was greater at the later time point (Table III). There was no correlation between the development of factor independence and the involvement of specific tissues in the mice nor the time to becoming moribund.

Factor independent cells were assessed for evidence of auto-
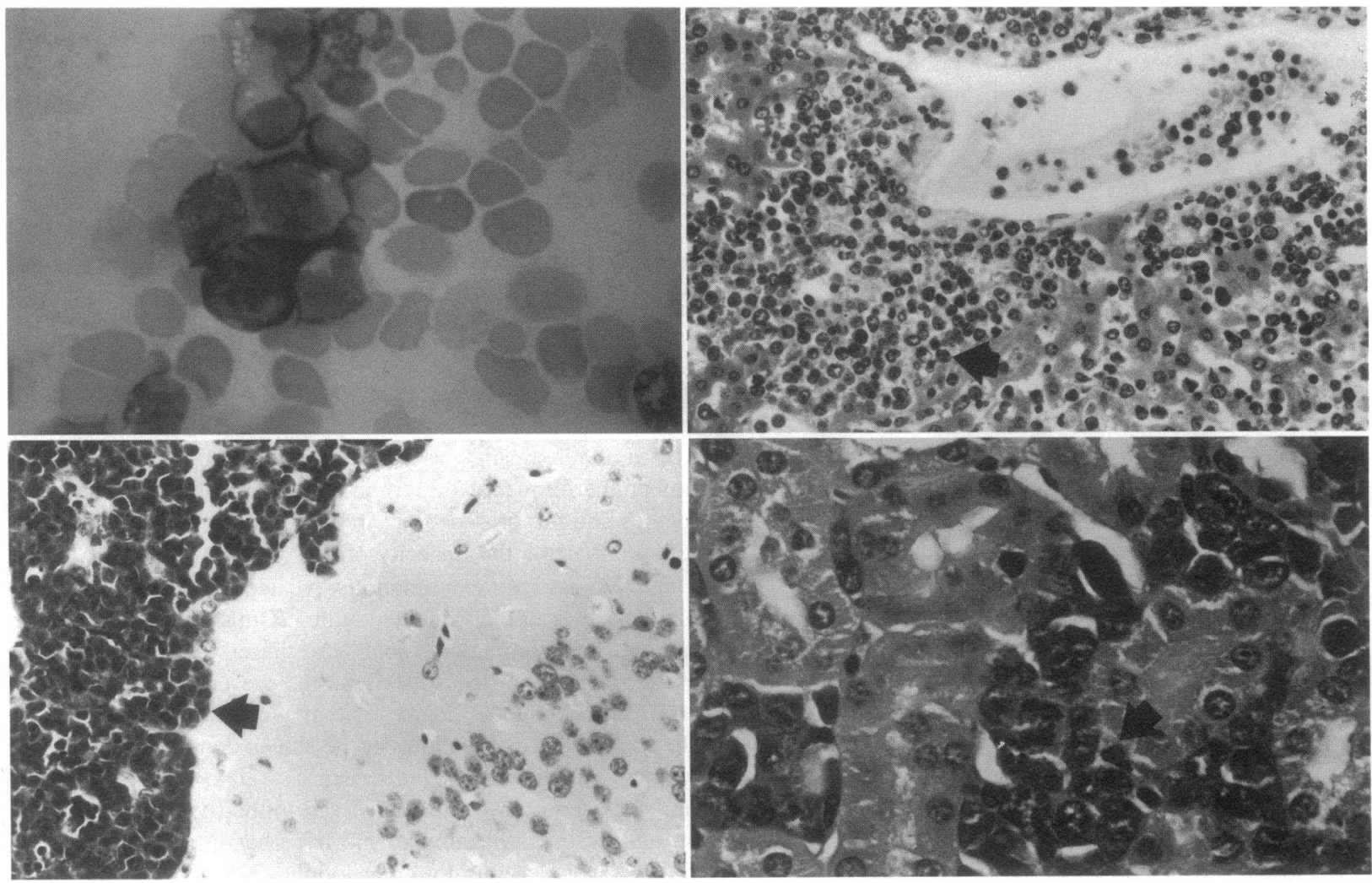

Figure 3. Tissue infiltration by $32 \mathrm{mKit}$ cells. The upper left panel shows the presence of blast like cells in the peripheral blood. A normal neutrophil can be seen in the top left hand corner. The upper right panel shows infiltration of the liver by leukemic cells. In this section the infiltration extended to the central vein, seen in the center of the panel. The bottom left panel shows infiltration of the meninges by leukemic cells. The bottom right panel illustrates kidney infiltration by 32DmKit cells. An arrow points to clusters of leukemic cells in the solid tissues. 
Table V. Weight of Spleens from Mice Injected with 32Dneo or 32DmKit Cells

\begin{tabular}{llcc}
\hline Group & \multicolumn{1}{c}{$\begin{array}{c}\text { Weight of individual spleen } \\
\text { in } \mathrm{mg}\end{array}$} & $\begin{array}{c}\text { Average weight } \\
\text { of spleen in } \mathrm{mg}\end{array}$ & $\begin{array}{c}P \text { value } \\
\text { (vs neo control) }\end{array}$ \\
\hline A4(-) & $290,670,850,510,920$ & $650 \pm 258$ & $<0.01$ \\
A4-250 & $625,1320,380,270,340$ & $587 \pm 431$ & $<0.01$ \\
A4 & $140,220,260,650,200$ & $294 \pm 204$ & $<0.01$ \\
K2 & $380,580,360,220$ & $385 \pm 148$ & $<0.01$ \\
K10 & $770,500,560,210$ & $510 \pm 231$ & $<0.01$ \\
K16 & $520,340,740$ & $533 \pm 200$ & $<0.01$ \\
Neo & $70,90,140,93,116,110$ & $103 \pm 24$ & \\
\hline
\end{tabular}

$A 4(-)$, mice were not irradiated. $A 4-250$, mice were irradiated to 250 cGy. All other groups of mice received 900 cGy of irradiation.

crine growth. Supernatants of factor-independent cells were tested for their ability to support the growth in suspension culture of 32D and 32DKit (A4) cells. We were unable to detect evidence of any biological activity. In addition we were unable to detect expression of $\mathrm{IL}-3$ or $\mathrm{KL}$ in factor independent and factor dependent cell lines either by northern blot analysis or RT-PCR.

Survival time of mice. Mice injected with kit expressing 32D cells became ill beginning $\sim 6 \mathrm{wk}$ after inoculation (Table VI). The average time for each group to become moribund was $56.6,62.6,76.3$, and $147 \mathrm{~d}$ for mice injected with A4, K2, K16, and K10 Kit expressing cells respectively. Animals injected with 32DmKit (K16) cells became moribund at a time significantly longer than animals injected with 32DKit (A4) or (K2) cells $(P<0.01$ and $<0.05$, respectively). The difference in time to death between 32DKit (A4) and (K2) cells was not significantly different. Animals injected with 32DKit K(10) cells had the longest survival. However, this difference may be due to the fact that these animals were injected with one half the number of Kit expressing cells than animals in the other groups.

Table VI. Survival Time of Mice Injected with 32Dneo and 32DmKit Cells

\begin{tabular}{llccc}
\hline Group & \multicolumn{1}{c}{ Days of survival } & $\begin{array}{c}\text { Average } \\
\text { survival }\end{array}$ & $\begin{array}{c}\text { No. of } \\
\text { cells } \\
\text { injected }\end{array}$ & $\begin{array}{c}\text { Relative Kit } \\
\text { expression } \\
\text { by cells }\end{array}$ \\
\hline & & $d$ & & \\
A4-900 & $50,51,51,64,67$ & 56.6 & $10^{6}$ & ++++ \\
K2 & $60,60,60,67,66$ & 62.6 & $10^{6}$ & ++ \\
K16 & $75,75,75,80$ & 76.3 & $10^{6}$ & + \\
K10 & $135,148,150,154$ & $>147$ & $5 \times 10^{5}$ & + \\
A4(-) & $135,135,140,157,>250$ & $>150$ & $10^{6}$ & ++++ \\
A4-250 & $67,80,80,80,86$ & 78.8 & $10^{6}$ & ++++ \\
Neo & $>250 \times 5,>300 \times 5$ & $>250$ & $10^{6}$ & - \\
& & & & \\
\hline
\end{tabular}

$A 4(-)$, mice injected with 32DmKit(A4) cells were not irradiated. A4-250, mice injected with 32DmKit(A4) cells were irradiated to 250 cGy. A4-900, mice injected with 32DmKit(A4) cells were irradiated to $900 \mathrm{cGy}$. All other groups of animals received $900 \mathrm{cGy}$. A4-900 vsl K2: $P=0.19$. A4-900 vs. K16: $P=0.007$. K2 vs K16: $P<0.05$. A4-900 vs $\mathrm{A4}_{250}: P<0.001$.

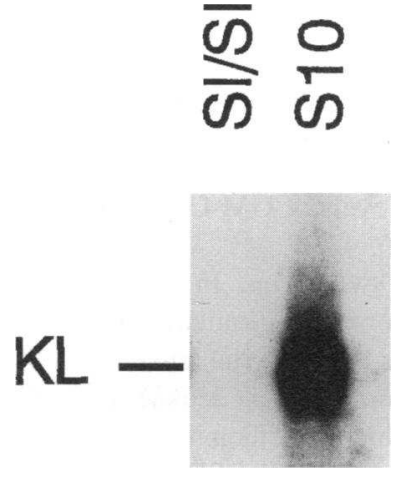

Role of irradiation. The majority of animals used in these studies received lethal irradiation. This was done in order to allow rapid engraftment of the 32Dmkit cells. However it is also possible that the irradiation was immunosuppressive, which then aided the growth of the 32DmKit cells. To test this, animals were prepared with no or sublethal irradiation and no added normal cells. In all cases there was the development of leukemia; however, the time to death was longer in the animals that received only $250 \mathrm{cGy}$ or no irradiation (Table VI).

Growth on bone marrow stroma cell lines. The above experiments demonstrate that cells expressing Kit and dependent on the presence of $\mathrm{mKL}$ or $\mathrm{mIL}-3$ for growth and survival, can proliferate in syngeneic animals. The most likely explanation for this is that the cells are being stimulated by $\mathrm{KL}$ expressed by endogenous mouse cells. An appropriate negative control for this would be to inject animals deficient in $\mathrm{KL}$ with 32DmKit cells. Unfortunately animals lacking $\mathrm{KL}$ are not viable (41), however stromal cell lines have been developed from such animals at the fetal stage of development. We compared the growth of 32mKit (A4) cells on S1/S14 cells and on S10 bone marrow stromal cells. The S1/S14 cells do not express any $\mathrm{KL}$ message while S10 cells produce abundant amounts of KL message (Fig. 4). The stromal cells were seeded onto $35 \mathrm{~mm}$ tissue culture dishes and when $80 \%$ confluent irradiated with $1.5 \mathrm{~Gy}$ to halt growth. $1 \times 10^{5} 32 \mathrm{DmKit}(\mathrm{A} 4)$ cells were seeded onto the stromal cells and the dishes observed daily for a period of $3 \mathrm{wk}$. Cells seeded onto dishes containing S10 cells became tightly adherent to the fibroblast like cells. Over the period of observation the cells maintained a healthy morphology and proliferated to eventually cover the entire fibroblast monolayer. Cells seeded onto S1/S14 cells did not become attached and over a period of $3 \mathrm{~d}$ became shrunken and died. 32Dneo cells did not attach and died rapidly when seeded onto either stromal cell line.

\section{Discussion}

The growth of human leukaemic cells in tissue culture is dependent upon the presence of specific growth factors $(1,2,7,24$, $42,43)$. This has led to the suggestion that the growth in vivo is also dependent upon the presence of growth factors. A number of models have been proposed for the presentation of growth factors in vivo. These include models by which the leukemic cells produce the growth factors that they respond to (an autocrine model) $(44,45)$ or host cells such as macrophages and stromal cells produce the required growth factors (paracrine model) (9). The autocrine hypothesis is supported by an animal model in which a GM-CSF/IL-3-dependent murine cell line 
was genetically engineered to produce GM-CSF (46). The parental cells were unable to grow in syngeneic animals while the modified cell line was able to grow and kill the animals (46). In addition to illustrating the potential for autocrine growth of leukemic cells this experiment demonstrated that in normal animals that there are insufficient levels of GM-CSF or IL-3 to support the growth of the cells $(46,47)$.

The paracrine model can take two forms. In one case the leukaemic cells may produce factors that stimulate the neighboring cells to make growth factors to which the leukemic cells can then respond. For example some human leukaemic cells have been found to produce IL-1 which may then induce stromal cells to produce high levels of GM-CSF, G-CSF, and M-CSF (48); these are all factors required for the growth of some leukaemic cells $(7,9,49-56)$. This model requires that the leukaemic cells aberrantly express a cytokine and express a receptor for the induced growth factor. To date there has not been any in vivo evidence for this model.

Another form of the paracrine model requires leukemic cells to express a receptor for a growth factor which is constitutively expressed in the normal animal. The experiments presented in this paper support this model.

The initial publication characterizing 32D cells described a cell line that required IL-3 for growth in culture and could not grow in syngeneic animals (25). Control experiments performed in this study confirmed that 32D cells injected into syngeneic animals could not produce a leukemic state. Moreover the bioassay used in this study showed that 32D cells could not be recovered from the bone marrow or spleen as early as 7 $\mathrm{d}$ and up to $180 \mathrm{~d}$ after injection. In contrast 32DmKit cells, which constitutively express $\mathrm{mKit}$ and grow in response to mIL-3 or mKL in culture, when injected into mice were able to survive and proliferate, resulting in the death of the animals. Death was due to the development of a leukaemic state characterized by decreased production of normal marrow elements and infiltration by leukemic cells of bone marrow, spleen, peripheral blood, brain, liver, lung, gut, and kidney.

The 32DmKit cells differed from 32Dneo cells by the expression of mKit on the cell surface. When injected into syngeneic animals the 32DmKit cells survived and proliferated in the mouse. Though there are a number of possible explanations for this we prefer the hypothesis that the survival and growth of the 32DmKit cells was due to interaction between Kit on the surface of the 32D cells and the in vivo expression of $K L$ by mouse stromal cells. This conclusion is supported by several observations. First, in tissue culture the 32Dneo cells survived in the presence of $\mathrm{mIL}-3$ but died when mKL was the only added growth factor. In contrast, 32DmKit cells survived and proliferated in mIL-3 or mKL, however in the absence of any added growth factor the cells died. Second, when seeded onto bone marrow stromal cell lines the 32DmKit but not 32Dneo cells survived and proliferated. However, when 32DmKit cells were placed on S1/S1 bone marrow stromal cells, that lack KL message and protein, the cells were unable to attach or survive. Taken together these studies indicate that the interaction between Kit and KL leads to the survival and growth of 32DmKit cells and that the most likely explanation for the growth of the cells in syngeneic animals is that the constitutively expressed Kit is interacting with $\mathrm{KL}$ presented by a variety of cell types in vivo $(18,19,57)$. The in vivo studies also demonstrates that there is insufficient IL-3 produced in the animal to maintain the viability of $32 \mathrm{Dneo}$ or $32 \mathrm{DmKit}$ cells.
The cell lines used in our studies varied in their ability to proliferate in vitro and in vivo. 32DmKit(A4) cells grew most rapidly and to a higher saturation density in culture than the other cell lines. These differences were further reflected by the time required for the animals to become moribund. Animals injected with 32DmKit(A4) cells became ill sooner than animals that had been injected with other cell lines. A possible explanation for the difference in behaviour of the cell lines is that the cells expressed different amounts of mKit on their surface. Both the ligand binding studies and the studies with the anti-Kit antibody, ACK-2, showed variations between the cell lines. $32 \mathrm{mKit}(\mathrm{A} 4)$ cells had the highest expression followed in order by 32DmKit(K2), 32DmKit(K16) and 32DmKit(K10). A correlation was found between the level of expression of mKit and the time to the development of leukemia, with high mKit expressers developing leukemia more rapidly.

Another feature of the 32D mKit expressing cells was the development of factor-independent cells during in vivo culture. In tissue culture we had not observed any factor independent cells in more than $1 \times 10^{8} 32 \mathrm{D}, 32 \mathrm{DmKit}$, or 32Dneo cells. Yet factor independent cells arose at a high frequency in vivo, in the mKit expressing cells. This was most evident in the cells that expressed low levels of mKit where cells from 3 of 6 animals at 3 wk and 6 of 6 animals at the time the animals were moribund were factor independent. This is in contrast to the cell lines expressing higher levels of mKit in which 0 of 6 animals at three weeks and 5 of 9 animals at the time the animals were moribund, contained factor-independent cells. The molecular events responsible for factor independence are not known. We were unable to detect $\mathrm{IL}-3$ or $\mathrm{KL}$ in conditioned medium or the presence of IL-3 or KL transcripts in RNA from any of the cell lines. The cell lines that we have developed will be useful in determining mechanisms by which cells become factor independent. The role that mKit and mKit ligand play in the development of factor independent leukemic cells is unknown. However, it is possible that interaction between receptor and ligand is playing a role in progression. Recently Huang and Wright have suggested that persistent interaction of a growth factor with its receptor may accelerate genetic changes in mouse fibroblasts (58).

Growth factor receptors have been implicated in the development of leukemia. Much attention has been given to identifying point mutations that may activate the functional activity of the receptor. In the case of FMS, mutations of amino acid 309 results in a constitutively active molecule (59). We and others have sought similar activating mutations in Kit. Despite these extensive studies there has been only one report of a human cell line in which a mutation of Kit results in constitutive activation (60). However, as demonstrated in our model, mutations of Kit probably are not necessary for Kit to play a role in vivo, as $\mathrm{KL}$ is expressed in a constitutive manner by a number of tissues including bone marrow stromal cells. In human leukemia the ready availability of $\mathrm{KL}$ eliminates the necessity for activating mutations of Kit. In normal development the interaction between Kit and its ligand terminates, as Kit is lost from the cell surface during the process of differentiation. However, in leukemic cells there is persistent expression of Kit. This persistent expression of Kit may come about as a result of blocked differentiation of the leukemic stem cell or a mutation in the promoter of Kit or a transactivating factor that regulates Kit. An understanding of how Kit expression is regulated, in- 
cluding a dissection of the Kit promoter will determine whether one or all of the mechanisms mentioned above are involved in the constitutive expression of Kit in human leukemia.

The model that we describe here illustrates that the continued expression of a normal growth factor receptor and its interaction with a normally expressed growth factor may be important in the development, maintenance, and progression of leukaemia. The model will be useful in determining the importance of other growth factor receptors and their ligands in the development of leukaemia. It is possible that the recently identified Flk-2/Flt-3 will behave in a manner similar to Kit(1012). The model will also be useful in determining whether it is possible to affect the growth of leukaemic cells in vivo by interfering with interactions between important pairs of growth factors and their ligands that are active in vivo.

\section{Acknowledgments}

This work was supported by a grant from the National Cancer Institute of Canada.

\section{References}

1. Kelleher, C., J. Miyauchi, G. Wong, S. Clark, M. D. Minden, and E. A. McCulloch. 1987. Synergism between recombinant growth factors, GM-CSF and G-CSF, acting on the blast cells of acute myeloblastic leukemia. Blood. 69:14981503.

2. Miyauchi, J., C. A. Kelleher, Y. Yang, G. G. Wong, S. C. Clark, M. D. Minden, S. Minkin, and E. A. McCulloch. 1987. The effects of three recombinant growth factors, IL-3, GM-CSF and G-CSF, on the blast cells of acute myeloblastic leukemia maintained in short-term suspension culture. Blood. 70:657-663.

3. Griffin, J. D., and B. Lowenberg. 1986. Clonogenic cells in acute myeloblastic leukemia. Blood. 68:1185-1195.

4. Anderson, D. M., S. D. Lyman, A. Baird, J. M. Wignall, J. Eisenman, C. Rauch, C. J. March, H. S. Boswell, S. D. Gimpel, D. Cosman, and D. E. Williams. 1990. Molecular cloning of mast cell growth factor, a hematopoietin that is active in both membrane bound and soluble forms. Cell. 63:235-243.

5. Zsebo, K. M., J. Wypych, I. K. Mcniece, H. S. Lu, K. A. Smith, S. B. Karkare, R. K. Sachdev, V. N. Yuschenkoff, N. C. Birkett, L. R. Williams et al. 1990. Identification, purification, and biological characterization of hematopoietic stem cell factor from buffalo rat liver-conditioned medium. Cell. 63:195-201.

6. Hoang, T., A. Haman, O. Goncalves, G. G. Wong, and S. C. Clark. 1988 Interleukin-6 enhances growth factor-dependent proliferation of the blast cells of acute myeloblastic leukemia. Blood. 72:823-826.

7. Hoang, T. 1988. Interleukin 1 enhances growth factor-dependent proliferation of the clonogenic cells in acute myeloblastic leukemia and of normal human primitive hemopoietic precursors. J. Exp. Med. 168:463-474.

8. Chang, H., H. A. Messner, X. Wang, C. Yee, L. Addy, J. Meharchand, and M. D. Minden. 1992. A human lymphoma cell line with multiple immunoglobulin rearrangements. J. Clin. Invest. 89:1014-1020.

9. Griffin, J. D., A. Rambaldi, E. Vallenga, D. C. Young, D. Ostapovicz, and S. A. Cannistra. 1987. Secretion of interleukin-1 by acute myeloblastic leukemia cells in vitro induced endothelial cells to secrete colony stimulating factors. Blood. 70:1218-1221.

10. Matthews, W., C. T. Jordan, G. W. Wiegand, D. Pardoll, and I. R. Lemischka. 1991. A receptor tyrosine kinase specific to hematopoietic stem and progenitor cell-enriched populations. Cell. 65:1143-1152.

11. Jordan, C. T., M. Gavin, N. A. Jenkins, N. G. Copeland, and I. R. Lemischka. 1991. A receptor tyrosine kinase cDNA isolated from a population of enriched primitive hematopoietic cells and exhibiting close genetic linkage to ckit. Proc. Natl. Acad. Sci. USA. 88:9026-9030.

12. Rosner, O., C. Schiff, M. J. Pebusque, S. Marchetto, C. Tonnelle, Y. Toiron, F. Birg, and D. Birnbaum. 1993. Human FLT3/FLK2 gene: cDNA cloning and expression in hematopoietic cells. Blood. 82:1110-1119.

13. Nocka, K., S. Majumder, B. Chabot, P. Ray, M. Cervone, A. Berstein, and P. Besmer. 1989. Expression of c-kit gene products in known cellular targets of $\mathrm{W}$ mutations in normal and $\mathrm{W}$ mutant mice-evidence for an impaired c-kit kinase in mutant mice. Genes and Dev. 3:816-826.

14. Nocka, K., J. C. Tan, E. Chiu, T. Y. Chu, P. Ray, P. Traktman, and P. Besmer. 1990. Molecular bases of dominant negative and loss of function mutations at the murine c-kit white spotting locus: W37, Wv, W41 and W. EMBO (Eur. Mol. Biol. Organ.) J. 9:1805-1813.

15. Bernstein, A., B. Chabot, P. Dubreuil, A. Reith, K. Nocka, S. Majumder,
P. Ray, and P. Besmer. 1990. The mouse W/c-kit locus. Ciba. Found. Symp. 148:158-66.

16. Anderson, D. M., D. E. Williams, R. Tushinski, S. Gimpel, J. Eisenman, L. A. Cannizzaro, M. Aronson, C. M. Croce, K. Huebner, D. Cosman, and S. D. Lyman. 1992. Alternate splicing of mRNAs encoding human mast cell growth factor and localization of the gene to chromosome 12q22-q24. Cell Growth \& Differ. 2:373-378.

17. Martin, F. H., S. V. Siggs, K. E. Langley, H. S. Lu, J. Ting, K. H. Okino, C. F. Morris, I. K. Mcniece, F. W. Jacobsen, E. A. Mendiaz et al. 1990. Primary structure and functional expression of rat and human stem cell factor DNAs. Cell. 63:203-211.

18. Keshet, E., S. D. Lyman, D. E. Williams, D. M. Anderson, N. A. Jenkins, N. G. Copeland, and L. F. Parada. 1991. Embryonic RNA expression patterns of the c-kit receptor and its cognate ligand suggest multiple functional roles in mouse development. EMBO (Eur. Mol. Biol. Organ.) J. 10:2425-2435.

19. Motro, B., D. Vanderkooy, J. Rossant, A. Reith, and A. Bernstein. 1991. Contiguous patterns of c-kit and Steel expression-analysis of mutations at the Wloci and Sl-loci. Development (Camb.). 113:1207.

20. Flanagan, J. G., D. C. Chan, and P. Leder. 1991. Transmembrane Form of the kit Ligand Growth Factor Is Determined by Alternative Splicing and Is Missing in the SI(d) Mutant. Cell. 64:1025-1035.

21. Wang, C., J. E. Curtis, E. A. McCulloch, and M. D. Minden. 1989. The expression of the proto-oncogene c-kit in the blast cells of acute myeloblastic leukemia. Leukemia. 3:699-702.

22. Broudy, V. C., N. Lin, K. M. Zsebo, N. C. Birkett, K. A. Sith, I. D. Bernstein, and T. Papayannopoulou. 1992. Isolation and characterization of a monclonal antibody that recognizes the human c-kit receptor. Blood. 79:338346.

23. Broudy, V. C., F. O. Smith, N. Lin, K. M. Zsebo, J. Egrie, and I. D. Bernstein. 1992. Blasts from patients with acute myelogenous leukemia express functional receptors for stem cell factor. Blood. 80:60-67.

24. Wang, C., P. Koistinen, G. S. Yang, D. E. Williams, S. D. Lyman, M. D. Minden, and E. A. McCulloch. 1991. Mast cell growth factor, a ligand for the receptor encoded by c-Kit, affects the growth in culture of the blast cells of acute myeloblastic leukemia. Leukemia. 5:493-499.

25. Greenberger, J. S., M. A. Sakakeeny, R. K. Humphries, C. J. Eaves, and R. J. Eckner. 1983. Demonstration of permanent factor dependent multipotential (erythroid/neutrophil/basophil) hematopoietic progenitor cell lines. Proc. Natl. Acad. Sci. USA. 80:2931-2935.

26. Karasuyama, H., and F. Melchers. 1988. Establishment of mouse cell lines which constitutively secrete large quantities of interleukin $2,3,4$ or 5 using modified cDNA expression vectors. Eur. J. Immunol. 1810:97-104.

27. Toksoz, D., K. M. Zsebo, K. A. Smith, S. Hu, D. Brankow, S. V. Suggs, F. H. Martin, and D. A. Williams. 1992. Support of human hematopoiesis in longterm bone marrow cultures by murine stromal cells selectively expressing the membrane-bound and secreted forms of the human homolog of the steel gene product, stem cell factor. Proc. Natl. Acad. Sci. USA. 89:7350-7354.

28. Henderson, A. J., A. Johnson, and K. Dorshkind. 1990. Functional characterization of two stromal cell lines that support B lymphopoiesis. J. Immunol. 145:423-428.

29. Alexander, W. S., S. D. Lyman, and E. F. Wagner. 1991. Expression of functional c-kit receptors rescues the genetic defect of $\mathrm{W}$ mutant mast cells. EMBO (Eur. Mol. Biol. Organ.) J. 10:3683-3691.

30. Reith, A. D., C. Ellis, S. D. Lyman, D. M. Anderson, D. E. Williams, A. Bernstein, and T. Pawson. 1991. Signal transduction by normal isoforms and W mutant variants of the Kit receptor tyrosine kinase. EMBO (Eur. Mol. Biol. Organ.) J. 10:2451-2459.

31. Miller, A. D., and J. Rosman. 1989. Improved retroviral vectors for gene transfer and expression. BioTechniques. 7:980-986.

32. Croaker, G. M., E. J. Wass, and H. J. Iland. 1990. Electric field mediated gene transfer into K562 cells: optimization of parameters affecting efficiency. Leukemia. 4:502-507.

33. Morgenstern, J. P., and H. Land. 1991. Advanced mammalian gene transfer: high titre retroviral vectors with multiple drug selection markers and a complementary helper free packaging cell line. Nucleic Acids Res. 18:3587-3596.

34. Yee, C., A. Biondi, H. Wang, N. N. Iscove, J. de Sousa, L. A. Aarde, G. G. Wong, S. D. Clark, H. A. Messner, and M. D. Minden. 1989. A possible autocrine role for interleukin 6 in two lymphoma cell lines. Blood. 74:798-804.

35. Chirgwin, J. M., A. E. Prxbyla, R. J. McDonald, and W. J. Rutter. 1979. Isolation of biochemically active ribonucleic acid from sources enriched in ribonuclease. Biochemistry. 18:5294.

36. Feinberg, A. P., and B. Vogelstein. 1983. A technique for radiolabeling DNA restriction endonuclease fragments to high specific activity. Anal. Biochem. 132:6-13.

37. Feinberg, A. P., and B. Vogelstein. 1984. A technique for radiolabeling DNA restriction endonuclease fragments to high specific activity. Anal. Biochem. 137:266-267.

38. Osburn, M. J., and R. Munson. 1974. Separation of the inner (cytoplasmic) and outer membranes of gram-negative bacteria. Methods Enzymol. 31:642.

39. Goding, J. W. 1986. Monoclonal Antibodies: Principles and Practice. 
Harcourt, Brace, Jovanovich, London, Orlando, New York, San Diego, Austin, Boston, Tokyo, Toronto.

40. Okada, S., H. Nakauchi. K. Nagayoshi, S. Nishikawa, Y. Miura, and T. Suda. 1991. Enrichment and characterization of murine hematopoietic stem cells that express c-kit molecule. Blood. 78:1706-1712.

41. Russell, E. S. 1979. Hereditary anemias of the mouse: a review for geneticists. Adv. Genet. 20:357-459.

42. McCulloch, E. A., M. D. Minden, J. Miyauchi, C. A. Kelleher, and C. Wang. 1991. Stem cell renewal and differentiation in acute myeloblastic leukemia. J. Cell Sci. Suppl. 10:267-281.

43. Delwel, R., L. Dorssers, I. Touw, E. R. Wagemaker, and B. Lowenberg. 1987. Human recombinant multilineage colony stimulating factor (Interleukin3): stimulator of acute myelocytic leukemia progenitor cells in vitro. Blood. 70:333-336.

44. Young, D. C., and J. D. Griffin. 1986. Autocrine secretion of GM-CSF in acute myeloblastic leukemia. Blood. 68:1178.

45. Young, D. C., K. Wagner, and J. D. Griffin. 1987. Constitutive expression of the granulocyte-macrophage colony-stimulating factor gene in acute myeloblastic leukemia. J. Clin. Invest. 79:100-106.

46. Lang, R. A., D. Metcalf, N. M. Gough, A. R. Dunn, and T. J. Gonda 1985. Expression of a hemopoietic growth factor cDNA in a factor-dependent cell line results in autonomous growth and tumorigenicity. Cell. 43:531-542.

47. Miyake, K., I. L. Weissman, J. S. Greenberger, and P. W. Kincade. 1991 Evidence for a Role of the Integrin VLA-4 in Lympho-Hemopoiesis. J. Exp. Med. 173:599-607.

48. Lee, M., G. M. Segal, and G. C. Bagby. 1987. Interleukin-1 incuces human bone marrow-derived fibroblasts to produce multilineage hematopoietic growth factors. Exp. Hematol. 15:983-988.

49. Kindler, V., J. Shields, D. Ayer, and G. J. Mazzei. 1991. Growth regulation of the AML-193 leukemic cell line: Evidence for autocrine production of granulocyte-macrophage colony-stimulating factor (GM-CSF), and inhibition of GMCSF-dependent cell proliferation by interleukin-1 (IL-1) and tumor necrosis factor (TNFalpha). Int. J. Cancer. 47:450-454.

50. Migliaccio, G., A. R. Migliaccio, and J. W. Adamson. 1991. In vitro differentiation and proliferation of human hematopoietic progenitors: the effects of interleukins 1 and 6 are indirectly mediated by production of granulocytemacrophage colony stimulating factor and interleukin 3. Exp Hematol. 19:3-10.

51. Delwel, R., C. van Buitenen, M. Salem, R. Oosterom, I. Touw, and B Lowenberg. 1990. Hemopoietin-1 activity of interleukin-1 (IL-1) on acute myeloid leukemia colony-forming cells (AML-CFU) IN VITRO: IL-1 induces production of tumor necrosis factor- $\alpha$ which synergizes with IL-3 or granulocytemacrophage colony-stimulating factor. Leukemia. 4:557-560.

52. Beauchemin, V., L. Villeneuve, J. C. Rodriguez-cimadevilla, D. Rajotte, J. S. Kenney, S. C. Clark, and T. Hoang. 1991. Interleukin-6 production by the blast cells of acute myeloblastic leukemia: regulation by endogenous interleukin1 and biological implications. J. Cell Physiol. 148:353-361.

53. Bradbury, D., B. Gareth, R. Koslowski, L. Reilly, and R. Nigel. 1990. Endogenous interleukin-1 can regulate the autonomous growth of the blast cells of acute myeloblastic leukemia by inducing autocrine secretion of GM-CSF. Leukemia. 4:44-47.

54. Cozzolino, F., A. Rubartelli, D. Aldinucci, R. Sitia, M. Torcia, A. Shaw, and R. Di Guglielmo. 1989. Interleukin 1 as an autocrine growth factor for acute myeloid leukemia cells. Proc. Natl. Acad. Sci. USA. 86:2369-2373.

55. Sakai, K., T. Hattori, M. Matsuoka, N. Asou, S. Yamamoto, K. Sagawa, and K. Takatsuki. 1987. Autocrine stimulation of interleukin lbeta in acute myelogenous leukemia cells. J. Exp. Med. 166:1597-1602.

56. Kitamura, T., F. Takaku, and A. Miyajima. 1991. IL-1 Up-Regulates the Expression of Cytokine Receptors on a Factor-Dependent Human Hemopoietic Cell Line, TF-1. Int. Immunol. 3:571-577.

57. Ray, P., K. M. Higgins, J. C. Tan, T. Y. Chu, N. S. Yee, H. Nguyen, E Lacy, and P. Besmer. 1991. Ectopic Expression of a c-kitW42 Minigene in Transgenic Mice-Recapitulation of W-Phenotypes and Evidence for c-kit Function in Melanoblast Progenitors. Genes \& Dev. 5:2265-2273.

58. Huang, A., and J. A. Wright. 1993. K-fgf proto-oncogene expression induces gene amplification. Proc. Am. Assoc. Cancer Res. 34:499.

59. Sherr, C. J. 1990. Colony-stimulating factor-1 receptor. Blood. 75:1-12.

60. Furitsu, T., T. Tsujimura, T. Tono, H. Ikdea, H. Kitayama, U. Koshimizu, H. Sugahara, J. H. Butterfield, L. K. Ashman, Y. Kanayama, Y. Matsuzawa, Y. Kitamura, and Y. Kanakura. 1993. Identification of mutations in the coding sequence of the proto-oncogene c-kit in a human mast cell leukemia cell line causing ligand-independent activation of c-kit product. J. Clin. Invest. 92:1736-1744. 